\title{
Ureteral Reconstruction in Goats Using Tissue-Engineered Templates and Subcutaneous Preimplantation
}

\author{
Paul K.J.D. de Jonge, MSc,' Marije Sloff, PhD, Heinz-Peter Janke, MSc, \\ Luuk R.M. Versteegden, MSc, Barbara B.M. Kortmann, MD, PhD,,3 Robert P.E. de Gier, MD,,3 \\ Paul J. Geutjes, PhD, ${ }^{1}$ Egbert Oosterwijk, PhD, ${ }^{1, *}$ and Wout F.J. Feitz, MD, PhD ${ }^{1,3, *}$
}

\begin{abstract}
Repair of long ureteral defects often requires long graft tissues and extensive surgery. This is associated with complications, including a lack of suitable tissue and graft site morbidity. Tissue engineering may provide an attractive alternative to the autologous graft tissues. In this study, ureteral repair using (preimplanted) tubular collagen-Vicryl templates was evaluated in a new goat model. Tubular templates were prepared from tubularized Vicryl meshes and $0.7 \%$ type-I collagen (length $=6 \mathrm{~cm}$, inner diameter $=6 \mathrm{~mm}$, wall thickness $=3 \mathrm{~mm}$ ). In total, twelve goats were used and evaluated after 3 months. Eight goats were implanted with the collagenVicryl templates and in four goats the templates were first preimplanted in the subcutis and subsequently used as ureteral graft. Template implantation was successful in $92 \%$ of the goats(11/12). During follow-up, $82 \%$ of the animals (9/11) survived without signs of discomfort. Two animals were sacrificed prematurely due to kidney perforation by the stent and urine leakage. Two other animals presented with stenosis of the neoureter due to stent migration. After preimplantation, the templates were remodeled mostly to autologous tissue with similar mechanical characteristics as the native ureter. Goats grafted with preimplanted templates presented with predominantly healthy kidneys, whereas the goats grafted with the collagen-Vicryl templates presented with fibrotic and inflamed regions in the kidneys. The use of preimplanted tissue templates showed favorable results compared with direct functional implantation of the templates. Partial remodeling toward autologous tissue and similar mechanical characteristics likely improved the integration in the ureteral tissue. Preimplantation of tissue-engineered templates should therefore be considered when two-stage procedures using a nephrostomy catheter are indicated or when planning allows for additional time to treatment.
\end{abstract}

Keywords: ureter reconstruction, large animal model, tissue engineering, collagen, preimplantation, scaffold

\section{Introduction}

$\mathbf{U}$ RETERAL TRAUMa CAN lead to severe problems, including urinoma, sepsis, and even kidney loss. While these traumas are relatively rare, they do account for $\sim 3 \%$ of all urogenital traumas. Iatrogenic injury is the main cause, with hysterectomy during gynecological surgeries accounting for about $73 \%$ of all injuries to the ureter ${ }^{1-3}$ Primary repair is often possible when the injury is recognized, but in $33-88 \%$ of the cases injury is not recognized during the surgery. ${ }^{4,5}$ Depending on the time between treatment, the type, and the location of the injury, different treatment options are available. Primary end-to-end anastomosis is often only possible shortly after the injury or in very short distance injuries. More severe damage requires extensive and challenging procedures, such as a Boari flap, transureteroureterostomy, or ileal interposition. ${ }^{6,7}$ Especially when donor tissue such as the ileum is used, the complication rate is as high as $40 \%$ and almost all patients need an intervention to treat obstruction after surgery, ${ }^{8}$ emphasizing the need for alternative approaches. Tissue engineering may be a new source of graft tissue, but in the past three decades failure rates have been high, despite the use of many biomaterials and approaches. ${ }^{9}$

Collagen is a biomaterial of interest because of its availability, plasticity, and low antigenicity. ${ }^{10}$ In previous studies in pigs, we evaluated tubular templates prepared from

Departments of ${ }^{1}$ Urology and ${ }^{2}$ Biochemistry, Radboud Institute for Molecular Life Sciences, Radboud University Medical Center, Nijmegen, The Netherlands.

${ }^{3}$ Radboudumc Amalia Children's Hospital, Radboud University Medical Center, Nijmegen, The Netherlands.

*These authors contributed equally to this work. 
collagen only, with or without cells and reinforced collagen-Vicryl tubes, with or without growth factors to repair ureteral deficits. While regeneration of the ureter was possible, the kidneys suffered from the procedure. Rapid wound healing and strong fibrosis were hypothesized to be the main factors causing hydronephrosis. ${ }^{11,12}$ Interestingly, in a recent urostomy study in pigs, preimplanted and subsequently translocated templates showed a more favorable outcome than direct implantation. ${ }^{13}$ In the current study, mature goats with a slower wound healing process were used to study (preimplanted) collagen-Vicryl templates for ureter tissue engineering.

\section{Materials and Methods}

\section{Template preparation}

Vicryl meshes (Ethicon) were tubularized around a stainless steel mandrel with Vicryl sutures $(\varnothing=8 \mathrm{~mm})$. Tubular $0.7 \%(\mathrm{w} / \mathrm{v})$ type I collagen (Collagen solutions, Eden Praire)-Vicryl templates $(1=7 \mathrm{~cm}$, lumen $\varnothing=6 \mathrm{~mm}$, wall $=3 \mathrm{~mm}$ ) were prepared as follows: homogenized collagen was cast in a cylindrical mold. Next, the Vicryl mesh and a $6 \mathrm{~mm}$ stainless steel mandrel were inserted, followed by freezing and freeze drying as described. ${ }^{14}$ After lyophilization the collagen was crosslinked using Carbodiimide ${ }^{15}$ and final hybrid templates were lyophilized a second time and packaged in blisters. All production steps were performed in a commercial clean room (EMCM). The final product was sterilized by ethylene oxide (Synergy Health). The degree of crosslinking was determined using a 2,4,6trinitrobenzene sulfonic acid assay in triplicate. Template ultrastructure was characterized by scanning electron microscopy (JEOL JSM-6310).

\section{Mechanical characterization}

Tensile ring tests were performed to investigate the (bio)mechanical properties of the hybrid templates and autologous tissues. Wet ring specimens of 1:10 mm of hybrid templates $(N=4)$, preimplanted templates $(N=4)$, and midsections of goat ureteral tissue $(N=9)$ were mounted between customized hooks (hook-to-hook distance: $6 \mathrm{~mm}$ ) of a tensile tester (Z2.5 TN; Zwick/Roell) equipped with a $2.5 \mathrm{kN}$ load cell. Test specimens were preconditioned radially $(50 \mathrm{~mm} /$ $\min$ ) by stretching $10 \times$ to $50 \%$ strain. Afterward, uniaxial load was applied until rupture. Force/displacement data were normalized to the test specimen dimensions to compute a stress/strain curve. The initial elastic modulus was calculated from the first slope of the curve. The ultimate tensile strength (UTS) and maximum strain at break were defined as the maximum stress and strain before failure. Data analysis was performed with SPSS statistics version 22 (IBM) using the one-way ANOVA test and Bonferroni post hoc analysis. $p<0.05$ was considered statistically significant.

\section{Animals}

The Nijmegen Medical Center Animal Ethics Committee approved the study protocol (RU-DEC-2014-223). All procedures were performed according to the Institute of Laboratory Animal Research guide for Laboratory Animals. ${ }^{16}$ In total twelve mature female Saanen goats, weighing 45-65 kg were used. They were housed in groups at the Institute's farm with a restricted diet and free access to water. The goats were transported to the animal laboratory the day before every procedure. Eight goats received a hybrid template, whereas in four other goats the template was preimplanted in the subcutis first. Goats were sedated through intravenous injection of $5 \mu \mathrm{g} / \mathrm{kg}$ medetomidine (Domitor; Orion Pharma) and $5 \mu \mathrm{g} / \mathrm{kg}$ propofol (Fresenius Kabi). Goats were intubated and anesthesia was maintained using $1.5 \%$ isoflurane (Pharmachemie). Subcutaneous injection of $0.5 \mathrm{mg} / \mathrm{kg}$ Meloxicam (Novem; Boehringer Ingelheim) was administered for analgesia. Intravenous antibiotics were administered (Amoxicillin, $10 \mathrm{mg} / \mathrm{kg}$; Aurobindo Pharma). During recovery, intramuscular injections of $5 \mu \mathrm{g} / \mathrm{kg}$ buprenorphine (AST Farma), 10,000 IE/kg benzylpenicillin (Procpen 30; DoPharma), and $15 \mu \mathrm{g} / \mathrm{kg}$ atipamezole (Orion Pharma) were given. Postoperatively, subcutaneous injection of $0.5 \mathrm{mg} / \mathrm{kg}$ Meloxicam and intramuscular injection of $10,000 \mathrm{IE} / \mathrm{kg}$ benzylpenicillin were given daily for 3 days.

\section{Surgical procedure}

Preimplantation. One month before ureter reconstruction, two hybrid templates $(1=7 \mathrm{~cm})$ were subcutaneously implanted in four goats on the right flank. A 5-cm incision was made $\sim 3 \mathrm{~cm}$ from the lower rib. Two separate pockets were created by spreading the subcutaneous tissue using long scissors toward the hind leg. Hybrid templates were placed over a silicon tube $(\varnothing=6 \mathrm{~mm})$ and were fixed to the tube using a 2-0 Vicryl suture on both ends. Next, the hybrid templates were placed and fixed in the pockets using 2-0 Vicryl sutures. Finally, the subcutis and skin were closed using 2-0 Vicryl sutures.

Functional implantation. A flank incision $(1=10 \mathrm{~cm})$ was made in the right flank of the goats $5 \mathrm{~cm}$ below the spine in parallel to the lower rib next to the preimplantation scar. The muscle layers were separated in the direction of the muscle fibers to enter the retroperitoneal space. The ureter was located and mobilized. Next, the ureter was stripped from the fatty layers for better visibility. The ureter was transected 5-11 cm from the kidney and both ends were spatulated. Hybrid templates or preimplanted templates $(1=6 \mathrm{~cm})$ were placed over a $4.7 \mathrm{Fr} / 22-32 \mathrm{~cm}$ multilength Double-J stent (Inlay Optima; Bard medical) followed by stent positioning in the kidney and bladder. Following technical complications related to stent placement, a C-arm was used to determine correct positioning of the stent in the kidneys for the final five goats. ${ }^{17}$ A tension-free anastomosis was created using 6-0 monocryl sutures (Ethicon). A 6-0 prolene suture was placed in the ureter $\sim 1 \mathrm{~cm}$ from the anastomosis site on both sides as markers. Fibrin glue (Tisseel; Baxter) was used to cover the anastomosis sites and templates to prevent leakage. The individual muscle layers, the subcutis, and skin were closed (2-0 Vicryl). The animals were followed closely for signs of discomfort.

Blood tests. After observed technical complications, blood creatinine, C-reactive protein (CRP), and sedimentation was analyzed in four animals to detect possible kidney failure and inflammation. Samples were retrieved preoperatively, postoperatively, and then weekly for up to 1 month. Samples were analyzed by the clinical chemistry laboratory of the Radboud University Medical Center. 


\section{Evaluation}

The goats were sacrificed by an overdose of intravenous pentobarbital $\sim 3$ months after the implantation procedure to study medium-term tissue regeneration. The urinary tract was harvested and evaluated macroscopically. Next, the size of the internal ureter and kidney morphology was investigated by radiology using iodinated contrast fluid (Iomeron 300; Bracco Imaging). Finally, tissue specimens of the neoureter, ureters, kidneys, and urinary bladder were harvested for histological evaluation. Specimens were fixed in $4 \%(\mathrm{v} / \mathrm{v})$ formaldehyde in phosphate buffered saline (PBS) (Boom) overnight and embedded in paraffin. The goats in which kidney perforation occurred with extensive urine leakage had unreliable tissue regeneration results and were omitted from further analysis (Table 1).

\section{Immunohistochemistry}

Sections of $4 \mu \mathrm{m}$ were cut and stained with Hematoxylin (Klinipath) and Eosin (Merck) for morphological analysis. Preimplanted templates and neoureter tissue after grafting were stained for pancytokeratin (AE1/AE3; Fisher Scien- tific), desmin (33; Biogenix), $\alpha$-smooth muscle actin ( $\alpha$ SMA, 1A4; Biogenix), and Verhoeff/Masson's Trichrome (Pathology; Radboudumc). In brief, antigen retrieval was performed using microwave treatment in sodium citrate $(\mathrm{pH} 6$, $10 \mathrm{~min}$ boiling and subsequently cooling to room temperature [RT]) for pancytokeratin immunohistochemistry. Peroxidase activity was blocked by incubation in $1 \%(\mathrm{v} / \mathrm{v}) \mathrm{H}_{2} \mathrm{O}_{2}$ (Merck) in PBS for $30 \mathrm{~min}$. Next, sections were incubated with $10 \%$ (v/v) rabbit serum for $10 \mathrm{~min}$, followed by $1 \mathrm{~h}$ incubation with primary antibodies, pancytokeratin (1:400), desmin (1:200), and $\alpha$ SMA $(1: 16,000)$. Secondary antibody (polyclonal rabbit anti-mouse immunoglobulins/HRP (Dako) was incubated for 30 min (1:100). Then, 3,3'-Diaminobenzidine (bright-DAB; Immunologic) was used to develop the slides. Finally, sections were counterstained using Hematoxylin for $5 \mathrm{~s}$. All antibodies and goat serum were diluted in PBS containing $1 \%(\mathrm{v} / \mathrm{v})$ bovine serum albumin (Sigma-Aldrich).

\section{Qualitative analysis}

Preimplanted tissues were investigated for template degradation, inflammation, and vascularization. Kidney sections were investigated for the occurrence of inflammation and

Table 1. Outcome of the Surgical Procedure for Each Goat

\begin{tabular}{|c|c|c|c|c|c|c|}
\hline & $\begin{array}{l}\text { Time in } \\
\text { experiment } \\
\text { (days) }\end{array}$ & Survival & $\begin{array}{l}\text { Distance } \\
\text { implant } \\
\text { to kidney } \\
\quad(\mathrm{cm})\end{array}$ & $\begin{array}{l}\text { Neoureter } \\
\text { size }(\mathrm{cm})\end{array}$ & Observations & $\begin{array}{l}\text { Included } \\
\text { for } \\
\text { histology }\end{array}$ \\
\hline \multicolumn{7}{|c|}{ No preimplantation } \\
\hline Goat 1 & 0 & $\begin{array}{l}\text { Sacrificed } \\
\text { in surgery }\end{array}$ & - & - & $\begin{array}{l}\text { Ureter ruptured in surgery during suturing, } \\
\text { defect become too long to repair }\end{array}$ & No \\
\hline Goat 2 & 84 & Survived & 5 & 1.5 & Double-J penetrated kidney, hydronephrosis & No \\
\hline Goat 3 & 67 & $\begin{array}{l}\text { Sacrificed } 2 \text { weeks } \\
\text { early }\end{array}$ & 8 & 1.5 & Double-J penetrated kidney & No \\
\hline Goat 4 & 42 & $\begin{array}{l}\text { Sacrificed } 6 \text { weeks } \\
\text { early }\end{array}$ & 11 & - & $\begin{array}{l}\text { Reached humane endpoint } \\
\text { (6 kg weight loss, signs of discomfort), } \\
\text { Double-J penetrated kidney, urinoma } \\
\text { on top of kidney }\end{array}$ & No \\
\hline Goat $5^{\mathrm{a}}$ & 91 & Survived & 7 & 1.5 & $\begin{array}{l}\text { Small diverticulum at anastomosis } \\
\text { site }\left(<1 \mathrm{~cm}^{2}\right)\end{array}$ & Yes \\
\hline Goat $6^{\mathrm{a}}$ & 91 & Survived & 7.5 & 2.0 & $\begin{array}{l}\text { Small diverticulum at anastomosis } \\
\text { site }\left(<1 \mathrm{~cm}^{2}\right)\end{array}$ & Yes \\
\hline Goat $7^{\mathrm{a}}$ & 94 & Survived & 7 & 1.5 & $\begin{array}{l}\text { Double-J stent migrated to neoureter } \\
\text { site, fistula around neoureter }\left(5-10 \mathrm{~cm}^{2}\right) \text {, } \\
\text { neoureter obstructed }\end{array}$ & No \\
\hline Goat $8^{\mathrm{a}}$ & 94 & Survived & 6 & 2.0 & $\begin{array}{l}\text { Double-J stent migrated to bladder, } \\
\text { complete obstruction of neoureter, } \\
\text { weight } \operatorname{loss}^{\mathrm{b}}(20 \mathrm{~kg})\end{array}$ & Yes \\
\hline \multicolumn{7}{|c|}{ Preimplantation } \\
\hline Goat 9 & $27+85$ & Survived & 7 & 3.5 & $\begin{array}{l}\text { Double-J stent penetrated kidney, } \\
\text { urinoma on top of kidney, distal } \\
\text { part of the stent in ureteral sheets } \\
\text { instead of ureteral lumen }\end{array}$ & No \\
\hline Goat 10 & $28+84$ & Survived & 7 & 1.5 & No complications & Yes \\
\hline Goat 11 & $31+81$ & Survived & 10.5 & 1.5 & No complications & Yes \\
\hline Goat $12^{\mathrm{a}}$ & $31+84$ & Survived & 9 & 2.0 & No complications & Yes \\
\hline
\end{tabular}


fibrosis, morphology of tubuli, and glomeruli. Neoureter sections were investigated for template degradation, tissue development (muscle, urothelium, vasculature), fibrosis, and inflammation. All sections were evaluated in a blinded fashion.

\section{Results}

\section{Templates}

Structure. Scanning electron microscopy (SEM) analysis showed highly porous honeycomb structures typical for collagen-based templates (Fig. 1). The tubularized Vicryl meshes were successfully integrated in the collagen as evidenced by collagen attaching to the Vicryl. Carbodiimide crosslinking stabilized the collagen resulting in a $49 \%$ free amine group reduction. After preimplantation, the templates were remodeled by host tissue and well vascularized. Collagen and Vicryl were partially degraded and a dense tissue layer formed on the inside and outside surrounding the remnants of the templates (Fig. 1).

Mechanical properties. All templates showed a J-shaped stress-strain curve in tensile ring tests (Supplementary Fig. S1; Supplementary Data are available online at www .liebertpub.com/tea). Templates showed an initial high elasticity followed by an uprising slope indicative of a rising stiffness before total failure. Hybrid templates showed a significantly higher initial $(p<0.0001)$ and UTS $(p<0$. 0001) compared with the other templates (Fig. 2). The difference between the initial tensile strength and UTS of preimplanted templates and goat ureteral segments was not significant ( $p=0.8$ and $p=0.13$, respectively).

\section{Animal surgery}

Success rate of the implantation procedure was $92 \%$ (11/ 12). One animal was sacrificed during surgery as the ureter wall ruptured and the ureter retracted, resulting in a defect $>10 \mathrm{~cm}$ that could not be repaired. During follow-up, $82 \%$ (9/11) survived without signs of discomfort. Two animals were sacrificed before the predetermined endpoint of 3 months due to rapid weight loss and signs of discomfort. Upon necropsy, kidney perforation by the stent and subsequent urine leakage from the kidney were observed. In two animals that reached the endpoint, the stent had perforated the kidney. One animal belonged to the group with hybrid templates, whereas the other received a preimplanted template. Based on this experience, X-ray-guided stent placement

FIG. 1. Material characterization. (A) Macroscopic view of a dry collagenVicryl template. (B) Crosssectional scanning electron microscopy image of a collagen-Vicryl template showing an open porous structure and good integration of the Vicryl mesh (arrow head). Scale bar $=500 \mu \mathrm{m}$. (C) Templates were placed over a silicon mandrel before preimplantation in the subcutis. (D) Macroscopic view after 1 month of preimplantation in the subcutis showing tissue encapsulation and vascularization. (E) Histological cross-section of preimplanted template.

Scalebar $=2000 \mu \mathrm{m}$. $(\mathbf{F})$

Magnification of crosssectional overview. * Indicates the Vicryl mesh. $\mathrm{X}$ Indicates collagen remnants. A dense tissue layer formed on the inside, sealing the template. Scalebar $=250 \mu \mathrm{m}$. Color images available online at www.liebertpub .com/tea
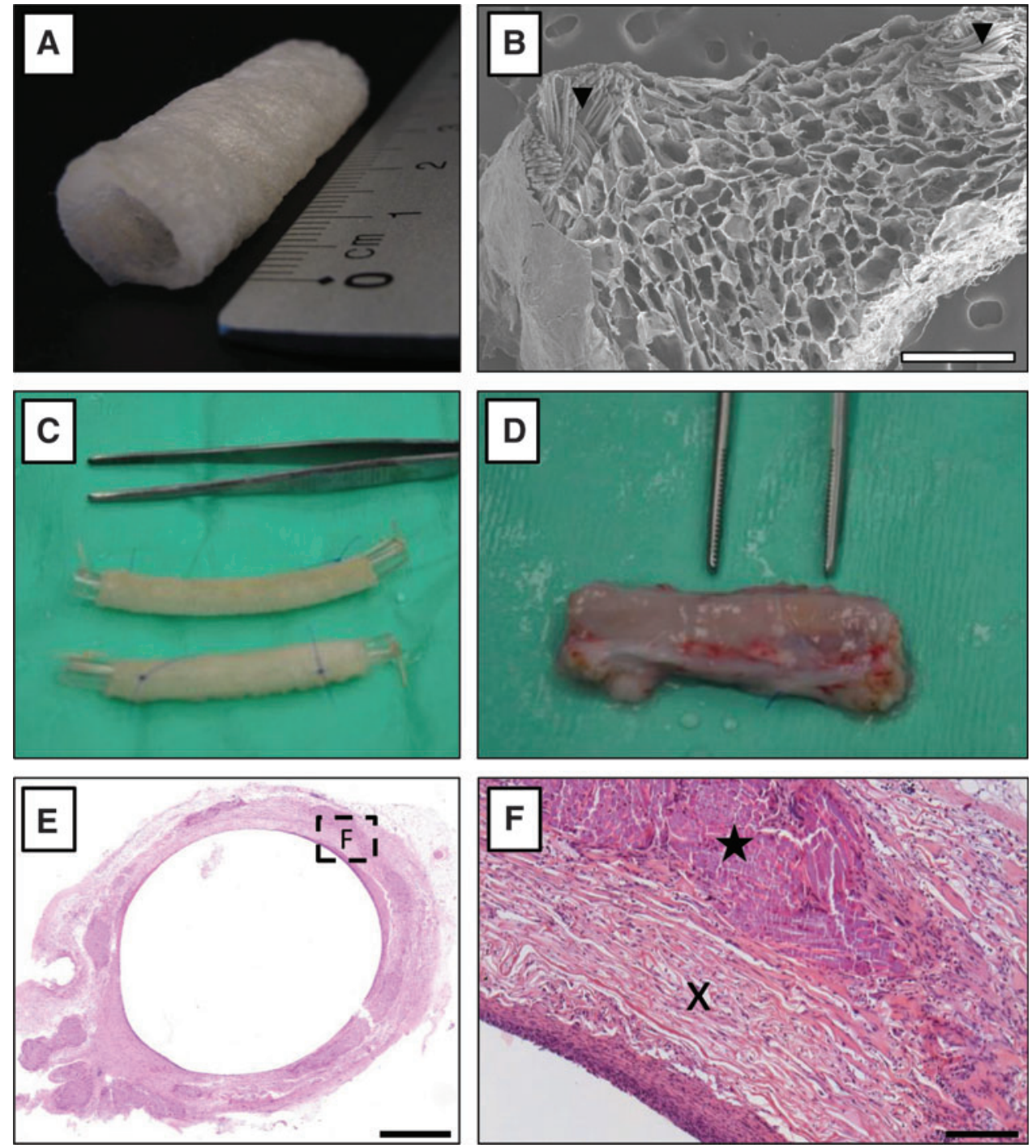

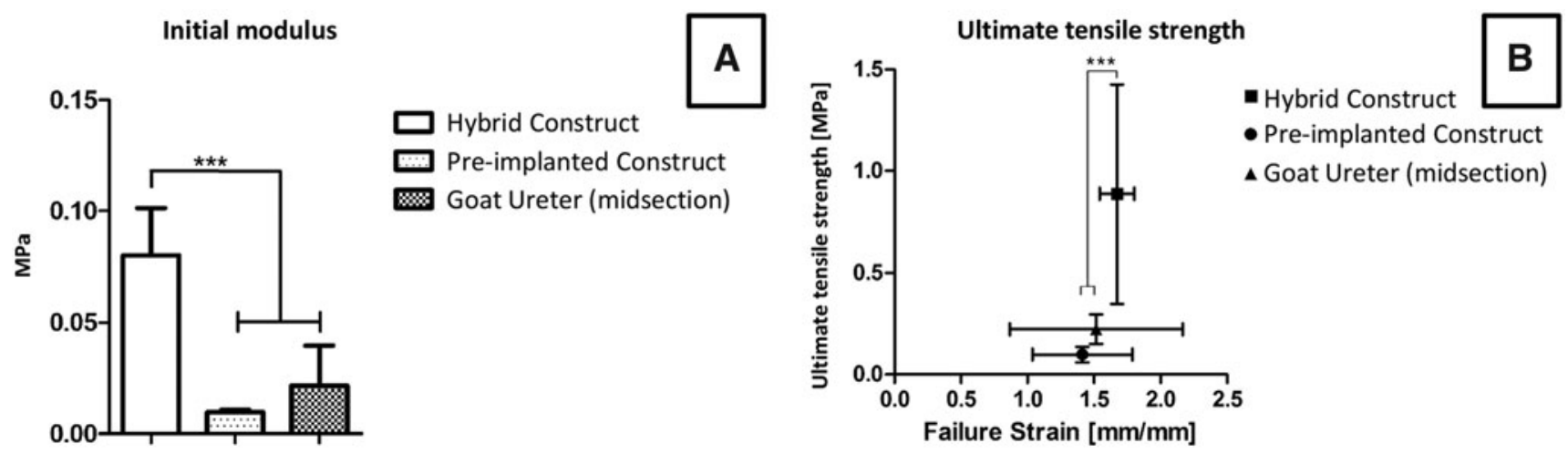

FIG. 2. Biomechanical analysis. (A) Initial modulus of collagen-Vicryl hybrid template, preimplanted template and native tissue. Hybrid templates show a significantly higher initial modulus compared with preimplanted $(p<0.0001)$ and native tissue $(p<0.0001)$. No difference was found between preimplanted templates and native tissue $(p=0.8)$. (B) UTS and strain at the failure point of collagen-Vicryl hybrid template, preimplanted template, and native tissue. Hybrid templates show a significantly higher UTS compared with preimplanted $(p<0.0001)$ and native tissue $(p<0.0001)$. No difference was found between preimplanted templates and native tissue $(p=0.13)$. No differences were found regarding strain at failure for any of the specimens $(p>0.99)$. UTS, ultimate tensile strength.

was introduced in the next five animals, after which no kidney perforation was observed. Two of these animals presented with stent migration, which led to stenosis of the neoureter. Five animals had no major complications. Results per animal are summarized in Table 1. Figure 3 shows the templates during implantation surgery.

Macroscopic evaluation. The appearance of the right kidneys was normal, regardless of the treatment modality (Fig. 4A, B, F). The shape, size, and color resembled the control kidneys, although small patches of dyschromia were observed sporadically, as well as a slightly thicker renal capsule. The proximal ureter was slightly dilated and the area of implantation showed signs of fibrosis in the animals grafted with the hybrid templates. The size of the regenerated tissue was $\sim 1.5 \mathrm{~cm}$ in both groups compared with the $6 \mathrm{~cm}$ graft. Small diverticula were observed at the anastomosis site when hybrid templates were used. Additionally, when hybrid templates were used, collagen remnants were found between the ureteral stent and the new tissue which resembled a gel-like substance. When preimplanted templates were used remnants were absent.

X-ray evaluation. No differences between the appearance of the right kidney connected to the reconstructed ureter and the left (control) kidney were observed (Fig. 4CE). The calyces were clearly distinguishable. The pyelum and proximal ureter were slightly dilated on the treated side. Small diverticula were observed in the group without preimplantation at the anastomosis site.

Blood analysis. Blood creatinine was slightly elevated $(95.0 \pm 8.5 \mu \mathrm{mol} / \mathrm{L})$ in all analyzed animals as a result of the surgery. Creatinine levels returned to normal $(64.8 \pm 10.1 \mu \mathrm{mol} / \mathrm{L}$, based on preoperative measurements) in all goats in the week thereafter. No changes were found for CRP $(<1 \mathrm{mg} / \mathrm{L})$ and sedimentation rate $(2 \mathrm{~mm} / \mathrm{h})$ at any time point in any of the analyzed goats.

\section{Histological evaluation}

Three goats could be included for histology in both groups (Table 2). The other goats had compromised regeneration due to complications with stenting (kidney perforation or stent migration), which resulted in excessive urine leakage (kidney perforation) or stenosis of the ureter (stent migration) and were therefore excluded from further analysis.

\section{Hybrid template group}

Kidneys. Morphological analysis of the kidney connected to the reconstructed ureter revealed fibrotic areas and inflammation in the renal cortex (Fig. 4G). In two goats, fibrosis and inflammation were also observed near the calyces.
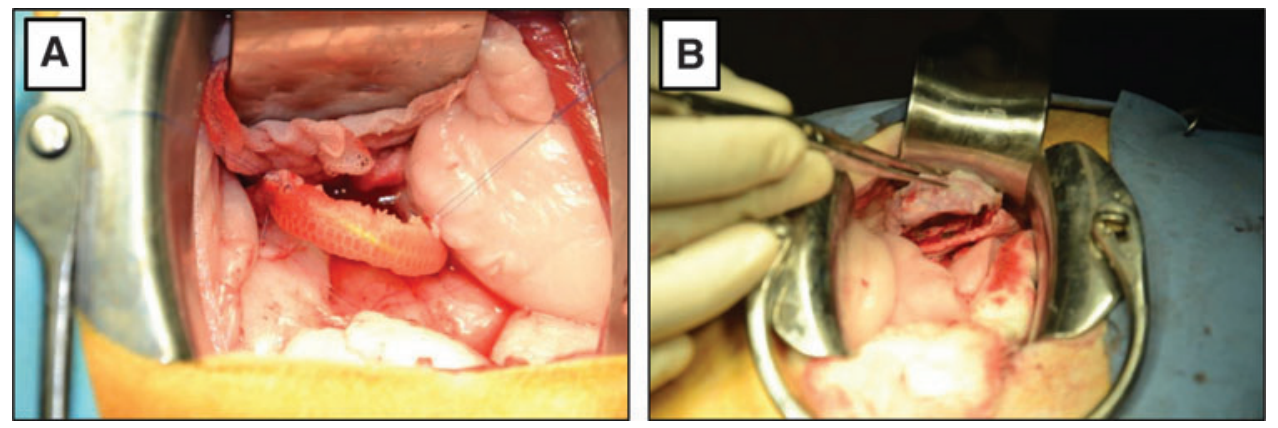

FIG. 3. Surgical procedure. (A) Implantation of a collagen-Vicryl template between two spatulated ureter ends. (B) Implantation of template between two spatulated ureter ends after preimplantation. Color images available online at www.liebertpub .com/tea 
FIG. 4. Evaluation overview 3 months after implantation. (A) Macroscopic view of the urological tract after implantation of a collagenVicryl template in the right ureter. (B) Macroscopic view of the urological tract after implantation of a preimplanted template in the right ureter. (C) X-ray image of the ureter and kidney after implantation of a collagenVicryl template. Arrowhead shows implantation site. (D) $\mathrm{X}$-ray image of the ureter and kidney after implantation of a preimplanted template. Arrowhead shows implantation site. (E) X-ray image of left ureter and kidney (control).

(F) Cross-section of both kidneys after implantation of a preimplanted template showing no differences between treated and control kidney. (G) Histological view of the kidney after implantation of a collagenVicryl template showing influx of inflammatory cells (X). (H) Histological view of the kidney after implantation of a preimplanted template showing healthy kidney tissue. $(\mathbf{G}, \mathbf{H})$ scale bar $=250$ $\mu \mathrm{m}$. Color images available online at www.liebertpub .com/tea
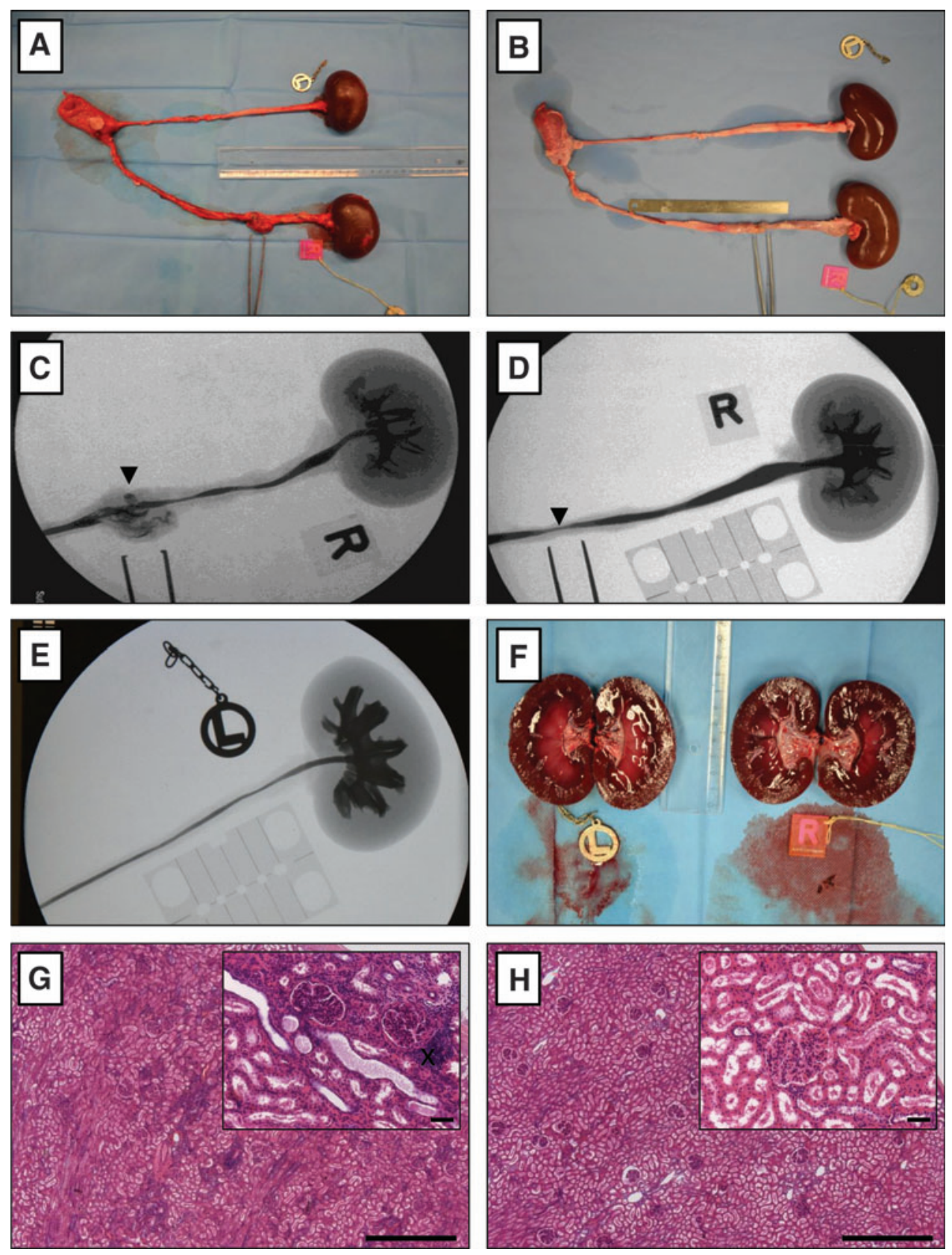

Neoureter. Integration of the hybrid template was poor (Fig. 5A). Although only a small amount of template remnants was found in the neoureter, many remnants were found extruded in the ureteral lumen (Fig. 5B). The newly formed tissue consisted mainly of connective tissue with $\alpha$-SMA-positive cells in parallel alignment to the ureteral lumen and extensive vascularization. Epithelial lining was absent as judged by the lack of panCK-positive cells (Fig. 5C, D). Smooth muscle cell ingrowth was limited to the anastomosis sites as evidenced by the minimal amount of desmin-positive cells growing into the neoureter (Fig. 5E, F). A small diverticulum $\left(<1 \mathrm{~cm}^{2}\right)$ was observed in two animals near the anastomosis site.

\section{Preimplantation group}

Kidneys. Morphologically the kidney tissue on the treated side was similar to native kidney tissue of the untreated side (Fig. 4H). The tubuli and glomeruli were almost completely intact and changes were minimal. In one goat, slight influx of inflammatory cells was observed in the renal cortex. In another goat, slight inflammation in one of the calyces was seen, whereas in the third goat inflammation was absent.

Neoureter. The preimplanted template integrated well in the ureter. The newly formed ureter tissue had a similar wall thickness compared with the native ureter (Fig. 6A). Smooth muscle tissue ingrowth was limited to the anastomosis sites as evidenced by minimal desmin-positive cell ingrowth into the neoureter (Fig. 6C). A single layered epithelium was observed throughout most of the luminal area as indicated by panCK-positive cells (Fig. 6B, D). The new tissue consisted mainly of connective tissue with $\alpha$-SMApositive cells and extensive vascularization (Fig. 6E). There was mild inflammation, particularly around the anastomosis 
Table 2. Outcome of Blinded Histological

Scoring of Representative Sections of THE

Templates After Preimplantation, After

FunCtional ImPLANTATION, AND THE KIDNEY ON THE TREATED SidE

\begin{tabular}{lcc}
\hline & $\begin{array}{c}\text { No } \\
\text { preimplantation }\end{array}$ & Preimplantation \\
\hline Preimplanted tissue & & \\
Collagen remnants & NA & + \\
Vicryl remnants & NA & \pm \\
Inflammation & NA & + \\
Vascularization & NA & \pm \\
New ureter tissue & & \\
Collagen remnants & \pm & \pm \\
Vicryl remnants & \pm & \pm \\
Inflammation & \pm & \pm \\
Vascularization & ++ & ++ \\
Muscle ingrowth & \pm & + \\
Epithelial lining & - & \\
Kidney & & ++ \\
Normal morphology & \pm & - \\
Inflammation & + & - \\
Fibrosis & + & \\
\hline
\end{tabular}

Supplementary Figure S2 shows a dot plot of the individual scores. NA, not applicable; -, not present; \pm , somewhat present; +, present; ++, abundant.

site. The template was mostly degraded as evidenced by the minimal collagen and Vicryl remnants (Table 2). No diverticulum was observed in any of the animals.

\section{Discussion}

There is a clear need for alternative treatment options for large ureteral defects when conventional surgical techniques cannot be used or donor tissues are not available. Nevertheless, ureteral tissue engineering is an understudied field in urogenital tissue engineering, possibly due to the lower number of patients in need for alternatives compared with other urogenital tissues, such as the urethra or the urinary bladder. ${ }^{18,19}$ In this study, we repaired an induced ureteral defect with (preimplanted) hybrid templates in adult goats. The main goal of a ureter reconstruction is to salvage the disconnected kidney to prevent kidney loss and restore the urinary tract. Therefore, the most important outcome of successful ureteral reconstruction is minimal kidney damage. In this large animal model we show that ureteral defect can be repaired with a tissue engineering approach $(6-\mathrm{cm}-$ long implant) with presumably minimal damage to the kidney. After ureteral repair with either direct grafting of a hybrid template or after preimplantation of this template, blood creatinine levels returned to preoperative values within 1 week and remained stable afterward, indicating good overall kidney function. However, morphological analysis of the tissue with a preimplanted template was superior to direct implantation of hybrid templates, suggesting that preimplantation followed by translocation is superior. Although blood creatinine levels normalized and histological analysis showed minimal kidney damage after reconstruction, future studies should include comprehensive functional studies, for example, measure the glomerular filtration rate to show potential differences in clearing rate between the left and right kidneys. ${ }^{20}$ Moreover, although follow-up of animals was 12 weeks, a reasonably long follow-up period, true long-term follow-up of at least 1 year is needed to adequately mimic the human situation.

Preimplantation procedures have previously shown promising results in tissue engineering, including ureteral reconstruction. ${ }^{21,22}$ In this study, we show the ability to create tissue tubes that were well vascularized and in which the initial inflammatory response had largely subsided before functional implantation. Through the insertion of a silicon mandrel, the lumen was maintained during this initial remodeling, preventing a change in template dimensions. After functional implantation, the connective tissue that covered the lumen of the neotissue templates may have protected the surrounding tissue from the toxic urine, preventing absorption of urine into the template remnants. ${ }^{23}$ Without preimplantation, the template can act as a sponge that absorbs urine, which may have a detrimental effect on the remodeling process by constantly irritating the surrounding tissue. After the remodeling phase, the preimplanted tissue had similar mechanical properties compared with the native ureter in contrast to the significantly stiffer hybrid templates. This higher stiffness may have led to a compliance mismatch that can cause local tissue stiffening and disturbed flow profiles resulting in hyperplasia. ${ }^{24,25}$ The combination of a high stiffness and constant exposure of the regenerating tissue to urine may have contributed to the formation of diverticula, extrusion of collagen into the lumen, and slower remodeling of the tissue. The compromised regeneration may also influence kidney outcome due to higher ureteral pressures.

Interestingly, collagen sponges have previously shown good results in other urogenital tissue engineering applications, such as urethra replacement and urinary bladder augmentation. $^{26,27}$ This difference may be explained by constant exposure to urine in the ureter compared with intermittent exposure during voiding in the urethra and folding of the urinary bladder when empty. Moreover, the anatomical characteristics are different, for example, the urethra is tightly surrounded by fascia and other penile tissues, whereas the ureter is positioned freely in the retroperitoneal space which makes it susceptible to mechanical stresses.

In this study, we studied adult goats instead of young pigs and showed a much more favorable outcome regarding the kidney. Due to their size, we previously used young pigs (36 months of age) for ureter reconstruction studies. ${ }^{28}$ Their fast growth and rapid wound healing may have negatively impacted the remodeling of the neoureter and resulted in hydronephrosis; an undesired outcome. Adult goats have a similar size and weight to these young pigs, but have the wound healing capacity of adult animals. By using adult animals, we may have better mimicked adult human tissue regeneration.

Smooth muscle tissue regeneration in the neoureter was limited compared with pigs. While smooth muscle tissue is important for ureter functionality, the regeneration of this tissue after ureteral defect repair may not be as important as initially hypothesized when only part of the contractile function is lost. In addition, the presence of the Double-J catheter may have made muscle regeneration redundant as it guarantees urine flow. Therefore, this catheter should be 
FIG. 5. Histological analysis 3 months after implantation of a collagen-Vicryl template. (A) Overview of the regenerated area. Newly formed tissue can be found between dashed lines. *Indicates a small diverticulum. $\mathrm{X}$ Indicates template remnants. Scale bar $=5 \mathrm{~mm}$. (B) Collagen remnants were found in the lumen of the ureter as indicated by X. (C) PanCK staining of normal tissue. (D) PanCK staining in the regenerated tissue. PanCK-positive cells were sparsely present. (E) Desmin staining at the anastomosis site (native tissue right of dashed line, new tissue left of dashed line) indicates limited muscle cell ingrowth. (F) Masson-Verhoeff staining confirms limited muscle ingrowth as muscle morphology changes from spindle-like bundles in the native tissue (right) to small patches in the new tissue (left). Muscle and epithelium in red, ECM in green. (B-F) Scale bar $=250 \mu \mathrm{m}$. ECM, extracellular matrix. Color images available online at www.liebertpub.com/tea
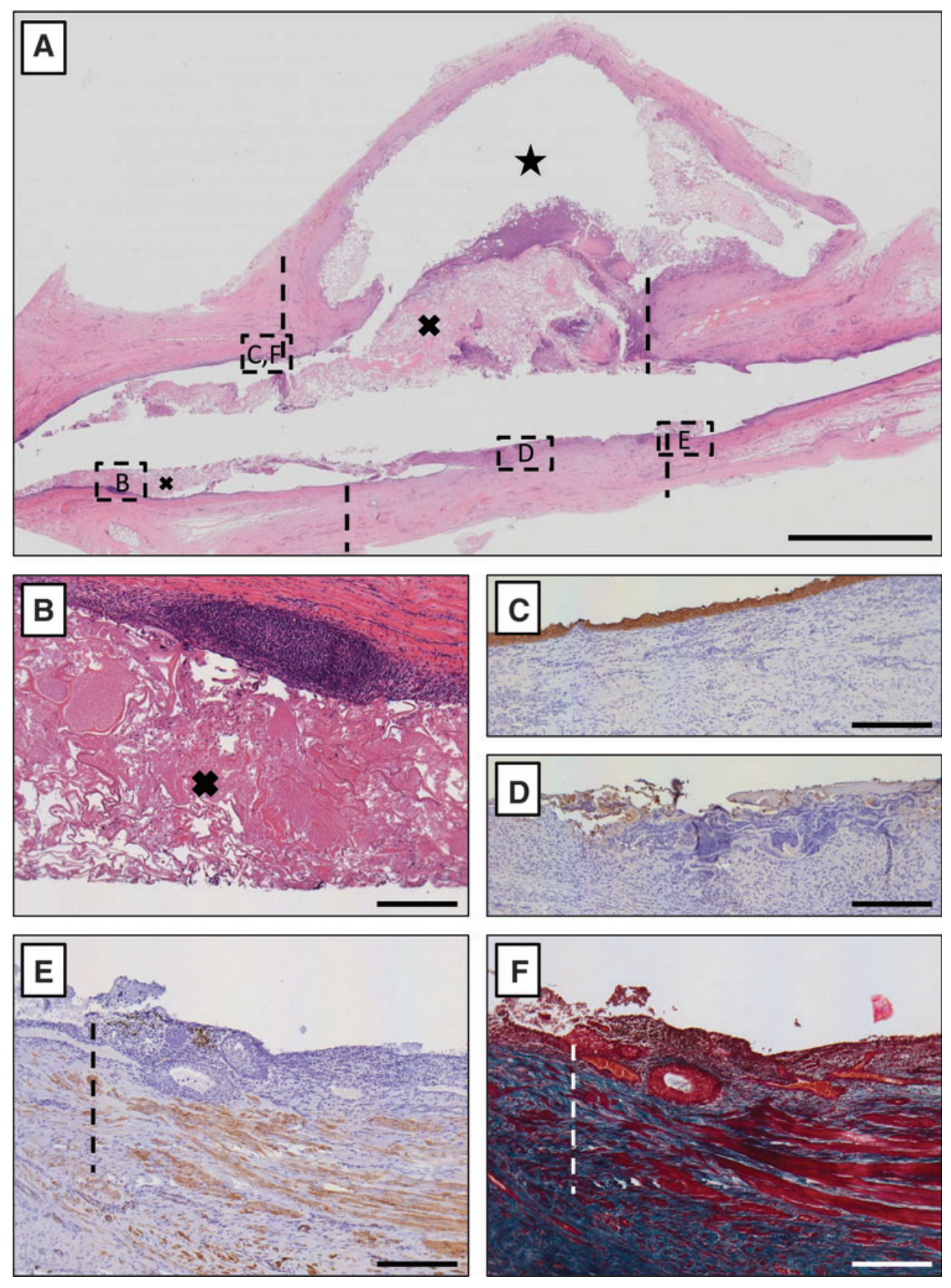

removed when studying longer time points. In the current study, the preimplanted tissue tube functioned adequately as ureter segment to maintain kidney integrity and function within the study time frame. Interestingly, graft shrinkage from 6 to $1.5 \mathrm{~cm}$ length had no detrimental effect on the kidneys. This may be related to the greater mobility of goats compared with pigs, which may improve the flow of urine. In general, the goat model appears to be a good alternative to the pig model when studying ureter reconstruction. However, the size of the kidney pyelum and the inner diameter of the ureter are much smaller than that of humans and pigs. In contrast to previous studies, no resistance was noticed when the guidewire perforated the kidney. Consequently, Double-J stent positioning was problematic in some cases, necessitating the use of human clinical protocol levels using X-ray and iodinated contrast fluids. ${ }^{17}$ Additionally, the small size of the ureter complicated anastomosis of the relatively oversized templates to the ureter. Smaller diameter templates may need to be considered for future experiments to better match template dimensions to the ureter.

While preimplantation of the templates showed promising results for ureteral repair, this method has a major drawback: In general, this type of reconstruction is mostly unforeseen and requires fast intervention. That is, it may not be possible to preimplant a template and wait for 1 month in all patients. Nevertheless, for severe and long ureteral defects a two-stage repair using a percutaneous nephrostomy catheter to drain urine is a standard treatment option. ${ }^{29}$ The time 

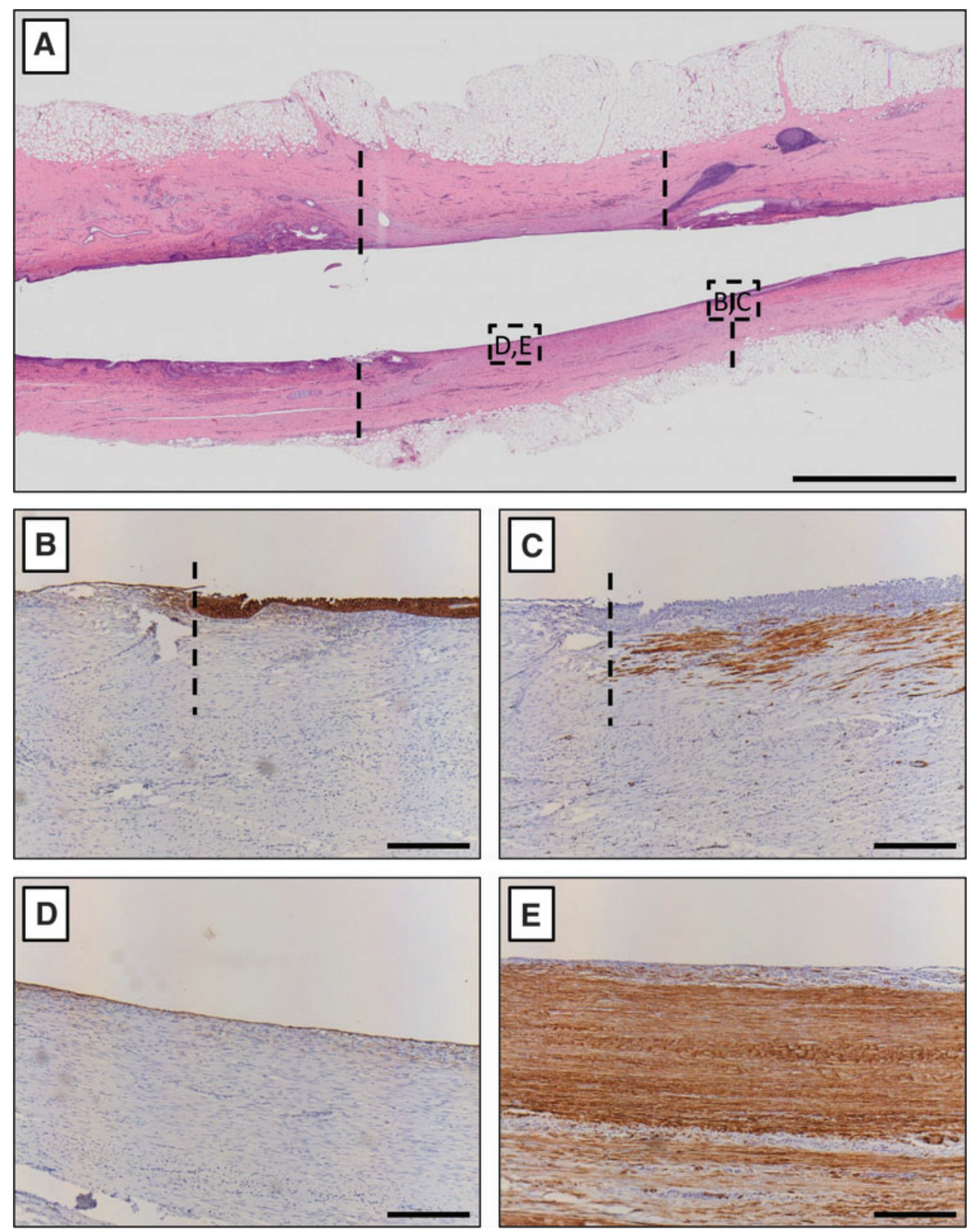

FIG. 6. Histological analysis 3 months after implantation of a preimplanted template. (A) Overview of the regenerated area. Newly formed tissue can be found between dashed lines. Scale bar $=5 \mathrm{~mm}$. (B) PanCK staining at the anastomosis site. Morphology changed from normal to singlelayered epithelium. (C) Desmin staining at the anastomosis site indicates limited muscle cell ingrowth. (D)

PanCK staining in the regenerated tissue. A singlelayered epithelium was observed throughout most of the regenerated tissue. (E) $\alpha$ Smooth muscle actin staining in the regenerated tissue shows alignment of fibroblasts in the extracellular matrix. (B-E) Scale bar $=$ $250 \mu \mathrm{m}$. Color images available online at www .liebertpub.com/tea between the two stages could be used for preimplantation. However, investigating this method is complicated in animals due to their mobility, which may lead to early elimination of the nephrostomy catheter. Alternatively, different templates that do not require preimplantation to be watertight and mimic the native tissue properties could provide a solution. Decellularization of native tissues may be an attractive alternative to investigate. ${ }^{30-32}$ In addition to being watertight and having similar tissue properties, beneficial bioactive compounds, such as growth factors, may remain in the tissue to stimulate wound healing and remodeling.

\section{Conclusion}

Ureteral reconstruction using preimplanted hybrid templates is superior to direct grafting in a goat model. This study showed that matching mechanical characteristics to the native tissue is superior to using stiffer templates and leads to better wound healing and tissue regeneration. Preimplantation of tissue-engineered templates should be considered when two-stage procedures are indicated or when the surgery can be planned. Finally, functional kidney analysis should be performed and longer follow-up should be studied to determine long-term outcome of ureteral defect repair using tissue engineering.

\section{Acknowledgments}

The authors would like to acknowledge the staff of the Radboud Central Animal Laboratory and the RIMLS MIC center for their support and the use of their facilities.

\section{Disclosure Statement}

No competing financial interests exist. 


\section{References}

1. Dowling, R.A., Corriere, J.N., and Sandler, C.M. Iatrogenic ureteral injury. J Urol 135, 912, 1986.

2. Elliott, S.P., and McAninch, J.W. Ureteral injuries: external and iatrogenic. Urol Clin N Am 33, 55, 2006.

3. Siram, S.M., Gerald, S.Z., Greene, W.R., et al. Ureteral trauma: patterns and mechanisms of injury of an uncommon condition. Am J Surg 199, 566, 2010.

4. Ostrzenski, A., Radolinski, B., and Ostrzenska, K.M. A review of laparoscopic ureteral injury in pelvic surgery. Obstet Gynecol Surv 58, 794, 2003.

5. Vakili, B., Chesson, R.R., Kyle, B.L., et al. The incidence of urinary tract injury during hysterectomy: a prospective analysis based on universal cystoscopy. Am J Obstet Gynecol 192, 1599, 2005.

6. Peters, P.C., and Sagalowsky, A.L. Genitourinary trauma. In: Walsch, P.C., Retick, A.B., Stamey, T.A., Vanghan, E.D.J., eds. Campbell's Urology. Philadelphia: WP Saunders, 1992, p. 2571.

7. Png, J.C., and Chapple, C.R. Principles of ureteric reconstruction. Curr Opin Urol 10, 207, 2000.

8. Armatys, S.A., Mellon, M.J., Beck, S.D., Koch, M.O., Foster, R.S., and Bihrle, R. Use of ileum as ureteral replacement in urological reconstruction. J Urol 181, 177, 2009.

9. Kloskowski, T., Kowalczyk, T., Nowacki, M., and Drewa, $\mathrm{T}$. Tissue engineering and ureter regeneration: is it possible? Int J Artif Organs 36, 392, 2013.

10. Cen, L., Liu, W., Cui, L., Zhang, W.J., and Cao, Y.L. Collagen tissue engineering: development of novel biomaterials and applications. Pediatr Res 63, 492, 2008.

11. Dalmose, A.L., Hvistendahl, J.J., Olsen, L.H., Eskild-Jensen, A., Djurhuus, J.C., and Swindle, M.M. Surgically induced urologic models in swine. J Invest Surg 13, 133, 2000.

12. Swindle, M.M., and Smith, A.C. Comparative anatomy and physiology of the pig. Scand J Lab Anim Sci 25, 11, 1998.

13. Sloff, M., Simaioforidis, V., Tiemessen, D.M., et al. Tubular constructs as artificial urinary conduits. J Urol 196, 1279, 2016.

14. Koens, M.J., Geutjes, P.J., Faraj, K.A., Hilborn, J., Daamen, W.F., and van Kuppevelt, T.H. Organ-specific tubular and collagen-based composite scaffolds. Tissue Eng Part C Methods 17, 327, 2011.

15. Pieper, J.S., Hafmans, T., Veerkamp, J.H., and van Kuppevelt, T.H. Development of tailor-made collagenglycosaminoglycan matrices: EDC/NHS crosslinking, and ultrastructural aspects. Biomaterials 21, 581, 2000.

16. Worlein, J.M., Baker, K., Bloomsmith, M., Coleman, K., and Koban, T.L. The eighth edition of the guide for the care and use of laboratory animals (2011); implications for behavioral management. Am J Primatol 73, 98, 2011.

17. Jonge, P.K.J.D.d., Sloff, M., Janke, H.P., et al. Clinical protocol levels are required in laboratory animal surgery when using medical devices: experiences with ureteral replacement surgery in goats. Lab Anim 51, 541, 2017.

18. Simaioforidis, V., de Jonge, P., Sloff, M., Oosterwijk, E., Geutjes, P., and Feitz, W.F. Ureteral tissue engineering: where are we and how to proceed? Tissue Eng Part B Rev 19, 413, 2013.

19. Versteegden, L., de Jonge, P., IntHout, J., et al. Tissue engineering of the urethra: a systematic review and meta-analysis of preclinical and clinical studies. Eur Urol 72, 606, 2017.
20. Stevens, L.A., Coresh, J., Greene, T., and Levey, A.S. Assessing kidney function-measured and estimated glomerular filtration rate. N Engl J Med 354, 2473, 2006.

21. Liao, W., Yang, S., Song, C., Li, X., Li, Y., and Xiong, Y. Construction of ureteral grafts by seeding bone marrow mesenchymal stem cells and smooth muscle cells into bladder acellular matrix. Transplant Proc 45, 730, 2013.

22. Zhang, J., Gu, G.L., Liu, G.H., et al. Ureteral reconstruction using autologous tubular grafts for the management of ureteral strictures and defects: an experimental study. Urol Int 88, 60, 2012.

23. Adamowicz, J., Kloskowski, T., Tworkiewicz, J., Pokrywczynska, M., and Drewa, T. Urine is a highly cytotoxic agent: does it influence stem cell therapies in urology? Transplant Proc 44, 1439, 2012.

24. Crapo, P.M., and Wang, Y. Physiologic compliance in engineered small-diameter arterial constructs based on an elastomeric substrate. Biomaterials 31, 1626, 2010.

25. Brugaletta, S., Gogas, B.D., Garcia-Garcia, H.M., et al. Vascular compliance changes of the coronary vessel wall after bioresorbable vascular scaffold implantation in the treated and adjacent segments. Circ J 76, 1616, 2012.

26. Roelofs, L.A., Oosterwijk, E., Kortmann, B.B., et al. Bladder regeneration using a smart acellular collagen scaffold with growth factors VEGF, FGF2 and HB-EGF. Tissue Eng Part A 22, 83, 2016.

27. Nuininga, J.E., Koens, M.J., Tiemessen, D.M., et al. Urethral reconstruction of critical defects in rabbits using molecularly defined tubular type I collagen biomatrices: key issues in growth factor addition. Tissue Eng Part A 16, 3319, 2010.

28. de Jonge, P., Simaioforidis, V., Geutjes, P., Oosterwijk, E., and Feitz, W. Ureteral reconstruction with reinforced collagen scaffolds in a porcine model. J Tissue Eng Regen Med 2016.

29. Goodwin, W.E., Casey, W.C., and Woolf, W. Percutaneous trocar (needle) nephrostomy in hydronephrosis. J Am Med Assoc 157, 891, 1955.

30. Gilbert, T.W., Sellaro, T.L., and Badylak, S.F. Decellularization of tissues and organs. Biomaterials 27, 3675, 2006.

31. Matsunuma, H., Kagami, H., Narita, Y., et al. Constructing a tissue-engineered ureter using a decellularized matrix with cultured uroepithelial cells and bone marrow-derived mononuclear cells. Tissue Eng 12, 509, 2006.

32. Chun, S.Y., Lim, G.J., Kwon, T.G., et al. Identification and characterization of bioactive factors in bladder submucosa matrix. Biomaterials 28, 4251, 2007.

Address correspondence to: Egbert Oosterwijk, PhD Department of Urology Radboud Institute for Molecular Life Sciences Radboud University Medical Center Geert Grooteplein Zuid 28 Nijmegen 6525 GA The Netherlands

E-mail: egbert.oosterwijk@ radboudumc.nl

Received: July 29, 2017 Accepted: October 25, 2017 Online Publication Date: December 21, 2017 